\title{
Impact of Internet Dependence on the Life Meaning System of Personality
}

\author{
Asya Berberyan ${ }^{1, *}$ \\ ${ }^{1}$ Russian-Armenian University, 123 Hovsep Emin street, Yerevan, 0051 Armenia
}

\begin{abstract}
The article discusses theoretical approaches to the characteristics of an addicted person, investigates the factors of dependence on the internet, the causes of addiction and psychological characteristics of an addicted person. Based on the study and analysis of scientific literature, the designation of dependence on the internet as a behavioral disorder that has a destructive effect on many aspects of human life is substantiated. The new formation of student age is the problem of the meaning of life. In recent years, the relevance of studying the transformation of the value system of students has increased, which makes it possible to predict the social and cultural consequences of the objective process of informatization, covering all spheres of human life. The idea of the models for the implementation of the pathological use of the internet, the issues of the defense mechanisms of the personality, the system of values and worldviews that determine the meanings of a person, significantly expanded the framework of the description and definition of the studied phenomenon. The aim of the current work is to study the relationship between internet addiction and the system of life meanings among students. Materials and methods: analysis of scientific literature, questionnaires, testing, including author's questionnaire supplemented by mat. statistical methods. In our study of the influence of internet technologies on internet addiction, on the value system of a student's personality, we identified differences in groups and correlations between internet addiction, defense mechanisms, personal characteristics and value orientations of the personality.
\end{abstract}

\section{Introduction}

A distinctive feature of modern society is integration into the world information community through the use of information and telecommunication technologies and global internet networks in the professional sphere as well as in everyday life. The social and cultural internet environment has features that influence the personality as a whole, in particular, its value system and worldview. In recent years, the study of the transformation of students' value system has increased in its relevance. It allows predicting the social and cultural consequences of the objective process of informatization that covers all spheres of

\footnotetext{
*Corresponding author: asya.berberian@gmail.com
} 
human life. Psychology considers the concept of "addiction" in two main directions: addiction as an individual variable, including the cognitive, motivational, emotional and behavioral characteristics of an addicted person, or as social addiction, which is associated with the satisfaction of a person's needs $[1,2]$.

The spread of the internet is contributing to psychological addiction problems. Internet dependence develops due to three factors: (1) accessible information, interactivity, (2) the possibility of anonymity of the transmitted information, (3) high level of trust in internet communication. In 1996, the official classification of mental illnesses recorded "cybernetic disorder", that is, the syndrome of "internet addiction" caused by stress, overwork due to a long stay at the computer, escape to the world of virtual reality [3]. Addiction can lead to any kind of psychological and physical illness. Among main reasons are long time spent in internet environment, bad mood, depression, etc. [4].

Currently, addiction is divided into several types: compulsive web surfing; virtual communication and online dating; replacement of real communication with virtual, constant participation in chats, communication in forums. This category of people has an inferiority complex and other mental health disorders, sexual internet addiction, gambling addiction. Neglected addiction can cause exhaustion of the nervous system and, in the future, psychosis. Goldberg was one of the first to name internet addiction as a behavioral disorder that has a devastating effect on many aspects of human activity. He was also the first to use "internet addiction" as a term [5]. Most often, this addiction is defined as a compulsive desire to enter the internet while offline, and the inability to leave it while on-line [6]. Many authors (V.A. Loskutova, N.A. Nosov, A.E. Voiskunsky, L.N. Yurieva) are unanimous in describing the main characteristics of internet addiction [7]. These include: violation of interpersonal relationships, impoverishment or complete cessation of social interactions, especially with significant people; shifting the center of the main activity to the virtual space; impossibility of social needs' satisfaction (metaneeds according to Maslow) [8]. The social phenomenon of escapism is closely connected with this mechanism - as the logical beginning of any addiction [9].

Internet addiction has common features with other forms of pathological addiction: deformation of the value-orientational sphere of personality; change in behavioral patterns, the predominance of negativism and irritability in contact with others; the increasing growth of tolerance (the amount of time that needs to be spent in the network to achieve satisfaction increases markedly over time) [10]. Some researchers have considered the phenomenon of internet addiction in the aggregate of psychological and physical symptoms that accompany it [8]. Thus, M. Orzak singled out symptomatic signs of internet addictions from the point of view of the phenomenological field of the personality, as well as the feelings and psychological states experienced by him [11]. These include the predominance of the positive emotional pole and the feeling of euphoria that can be observed when interacting with a computer; impossibility of arbitrary control and management of time spent on social networks; indifference to the preservation and maintenance of social contacts; concealment (or non-recognition) of the presence of a problem situation; the predominance of negative emotions when you are outside the network; violations of various spheres of activity: educational, professional, etc. [12, 13].

Arguing against this topic about the legitimacy of classifying internet addictions as an independent phenomenon, M. Griffiths argued that dependence on the internet is not an independent type of addiction, but only serves as a form of realization of other types of pathological attraction that the addict already has [14]. Continuing this idea, R. Davis [15] proposed a cognitive-behavioral model for the implementation of pathological internet use, which significantly expanded the scope of describing and defining this phenomenon. The problem of internet addictions is related to the issues of personal defense mechanisms. 
S. Freud fundamentally described defense mechanisms. His daughter, A. Freud considered defense mechanisms not only as innate features, but she expanded the understanding of defense mechanisms, when Ego is exposed to excessive activity of urges or affects, which are a danger for him, then the defense mechanism begins to work [16]. Through the work of her father and thanks to her own psychoanalytic experience, A. Freud concluded that when using defense mechanisms, conflicts are not removed, but fear still persists. Based on this, there is a high probability of the appearance of diseases, since a certain set of those techniques that protect the person, nevertheless, create a certain symptomatology. M. Klein proposed the following classification: the splitting of the object, projective, or identification itself, the rejection of mental reality and the claim to absolute power over the object [17]. Renowned psychoanalyst W. Reich noted that the entire structure of a person's character is a unified defense mechanism. The famous representative of ego psychology H. Hartmann also expressed his opinion on this matter [18]. He noted that the defense technique of Ego can simultaneously serve as a control over drives, and as an adaptation to the world around.

Psychologists consider psychological defense mechanisms as the most important forms for the reaction of an individual's consciousness in response to mental trauma [19]. According to some studies, psychological defense is a system of adaptive reactions of a personality, which is oriented at defensive change in such significant maladaptive components of relationships as cognitive, emotional, and behavioral [20]. There is one goal here that is to weaken their traumatic effects on the Self-concept, on the system of life meanings. Psychologists believe that the new formation of student age is the problem of the life meaning [21]. Also, an important new formation of youth is the emergence of life plans, and it manifests itself in the intention to consciously build one's own life as a manifestation of the beginning of the search for its meaning [20].

Value determines the life meanings of a person, forms a hierarchy of objects or phenomena according to the degree of significance for his life. The value system is a unique structure for each member of society. On its basis, the preferences of the individual are formed, guiding him in decision-making and behavior [21]. The value system is determined by a set of standards and criteria that a person is guided by throughout his life. Changes in the living conditions and environment of the individual leads to the emergence of new values, and sometimes to a complete or partial reassessment [22].

The value perception is significantly different in the current youth than in the previous generations. For example, according to the recent research, the most important values of young people are health, love, friendship and a happy family life, while the least important values are the beauty of nature and art, entertainment, creativity, and the happiness of others. Student age is a sensitive period for the further formation and development of lifevalue orientations [23]. Some scientists (E.V. Burmistrova, T.E. Reznik, I.A. Surina, N.A. Churkina and others) see perspectives of value orientation formation in the social and information aspect.

\section{Hypotheses}

We assume that:

1. there are differences between the level of internet addiction and the severity of the defense mechanisms of the personality in males and females;

2. there is a relationship between internet addiction and personality traits;

3. there are differences between the level of internet addiction and its awareness;

4. the groups of students using internet technologies for virtual communication, entertainment and games for more than 4-5 hours a day differ in the system of values from 
the groups of students who use these technologies less or mainly for the purpose of learning.

The goal of the current work: to study the relationship between internet addiction and the system of life meanings among students.

Methodological basis of the current study includes the concepts, theories and the main ideas described in the scientific works of B.G. Ananyev, O.N. Arestov, E.S. Balabanov, R. Burns, A.V. Gogolev, I.S. Kon and K. Young.

\section{Materials and methods}

(1) analysis of scientific literature, (2) questionnaires, testing that included such methods as personal differential (V.M. Bekhterev), diagnostics of internet addiction (K. Young), method of value orientations of Schwartz, author's questionnaire, (3) mathematical statistical methods.

We conducted a study with 86 students of various specialities of bachelor's and master's degrees. The participants included equal number of males and females: 43 male and 43 female students. The participants were divided into two groups. The first group consisted of students using internet technologies for more than 4-5 hours a day for the purpose of communication, entertainment and games. The second group included respondents who used internet technologies for less than 4-5 hours a day and exclusively for learning purposes.

\section{Results}

According to the results of the first questionnaire, we found that male participants had a higher level of dependence (33\% - high, 52\% - average level), while females were mostly characterized by an average level of dependence (11\% - high, 59\% - average level).

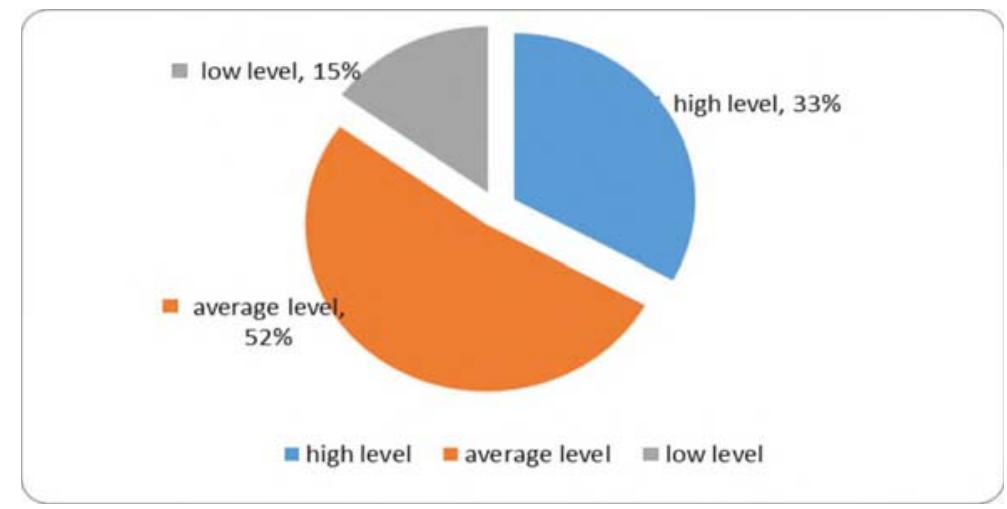




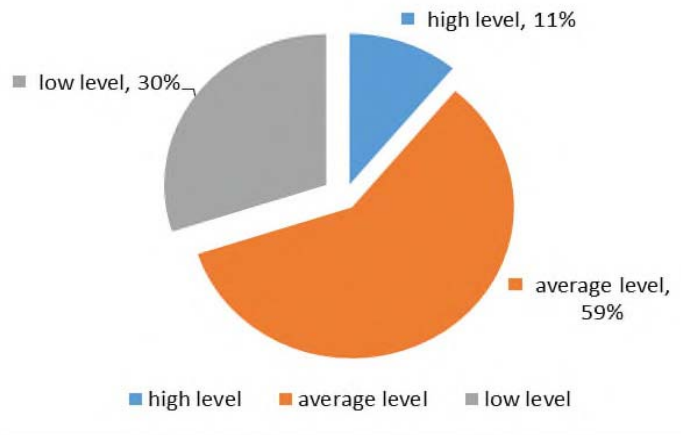

Fig. 1-2 . Internet Addiction Test Results S.Young in girls (group 1-2).

The results of the Personal differential questionnaire (V. M. Bekhterev) showed that the first group had: Factor "Assessment" (high level - 37\%, average level - 47\%, low level 16\%); Factor "Strength" (high level - 33.3\%, average level - 51.8\%, low level - 14.9\%); Factor "Activity" (high level - 27.8\%, average level - 51.8\%, low level - 20.4\%. In the second group: Factor "Assessment" (high level - 44\%, average level - 36\%, low level $20 \%$ ); Factor "Strength" (high level - 38.9\%, average level - 37\%, low level - 24\%); Factor "Activity" (high level - 18.5\%, average level - 55.6\%, low level - 25.9\%).

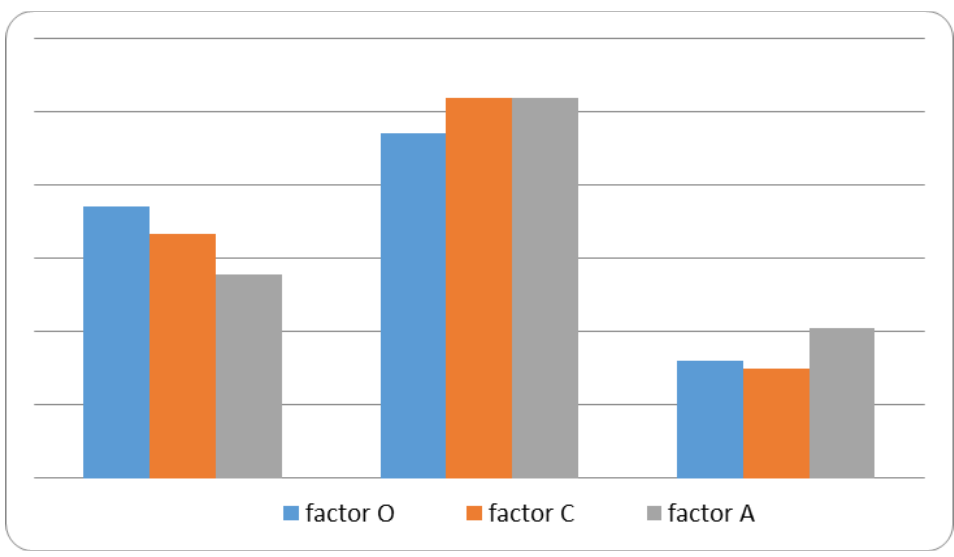

Fig. 3 . Test results "Personal differential" among boys (group 1)

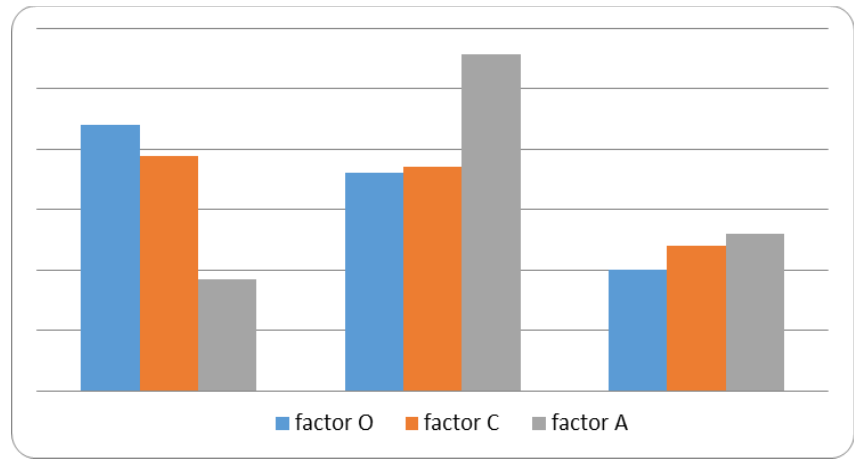

Fig. 4 . Test results "Personal differential" among girls (group 2) 
According to the results of the third method, we have identified that in males, the main defense mechanisms are projection, substitution, intellectualization, while in females projection and denial.

Based on the results of identifying the values of the first group of students, they can be classified as follows: openness to changes $35.9 \%$; hedonism and self-aggrandizement $35.6 \%$; self-superiority and kindness $21.4 \%$; conformism $7.1 \%$. The results of the second group of students' values can be classified as follows: hedonism and self-aggrandizement (49.9\%); openness to changes $(25.2 \%)$; self-superiority (16.5\%); striving for safety $(8.3 \%)$.

Table 1. Results of the study of defense mechanisms in young men (group 1)

\begin{tabular}{|l|cc|}
\hline Scale & Raw score & Percentiles \\
\hline Denial & 6 & 79 \\
\hline Suppression & 7 & 92 \\
\hline Regression & 3 & 35 \\
\hline Compensation & 2 & 37 \\
\hline Projection & 12 & 96 \\
\hline Substitution & 8 & 97 \\
\hline Intellectualization & 8 & 87 \\
Reactive formations & 4 & 76 \\
\hline
\end{tabular}

According to the results of the author's questionnaire, we have revealed the following results: the overwhelming number of participants spend a long time at the computer among the respondents of the 1 st group - 58\%, the 2nd group - 49\%; and from 2 to 3 hours - a very small percentage of students in both groups.

Table 2. Results of the study of defense mechanisms in young girls (group 2)

\begin{tabular}{|lcc|}
\hline Scale & Raw score & Percentiles \\
\hline Denial & 9 & 97 \\
\hline Suppression & 5 & 76 \\
\hline Regression & 4 & 53 \\
\hline Compensation & 2 & 37 \\
\hline Projection & 12 & 96 \\
\hline Substitution & 4 & 65 \\
\hline Intellectualization & 8 & 87 \\
\hline Reactive formations & 8 & 99 \\
\hline
\end{tabular}

When asked about the feeling of emptiness, bad mood and irritability while working at the computer / in internet environment, the answer was positive in the first group - $58 \%$, in the second $-48 \%$ of students, a third group answered negatively, the rest found it difficult to answer. The participants revealed that it was easier for them to communicate with people internet (48\% and $61 \%$ ), and in real communication $-52 \%$ and $39 \%$.

When asked about the purpose of using the Internet, students indicated their preferences: entertainment (36\% and 35\%), communication (34\% and 33\%), to a lesser extent, learning (30\% and 32\%). Noteworthy, the participants had many friends in real communication: in the first group $-63 \%$, in the second $-48 \%$, and in virtual communication 
$-37 \%$ and $52 \%$. An insignificant percentage of students (20\% and $37 \%)$ admited that their dependence on the internet was uncontrollable. A desire to spend more time in the real world was expressed by $25 \%$ in the 1 st group and $39 \%$ in the 2 nd.

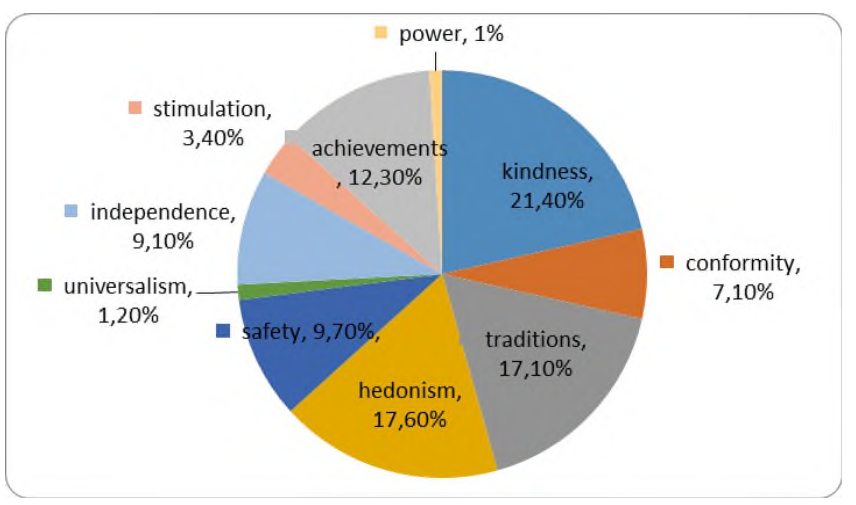

Fig. 5 . Results of the study of values among young males (group 1)

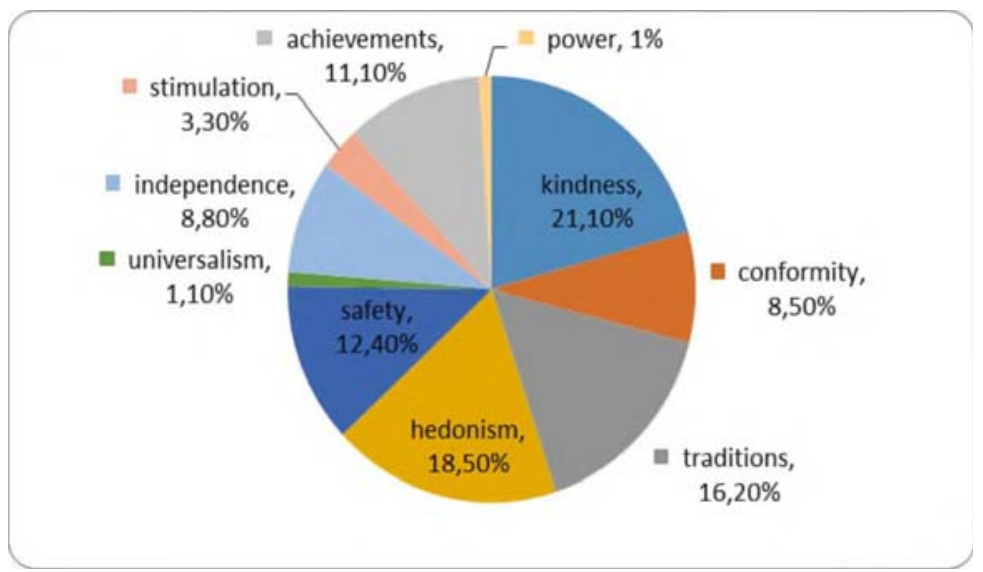

Fig. 6 . Results of the study of values among young females (group 2).

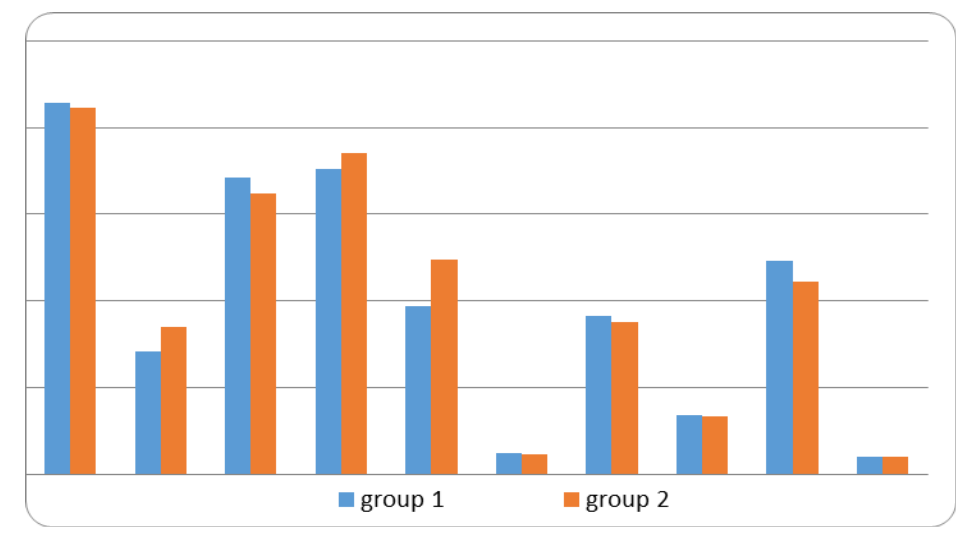

Fig. 7. Graph 1. Results of the respondents' values study of the two groups.

To test the hypotheses, we conducted a correlation analysis and found: 1 . there is a negative average correlation between internet addiction and defense mechanisms, $r(84)=-$ 
41. 2. there is a slight positive correlation between internet addiction and personality traits, $\mathrm{r}(84)=.26$. 3. there are differences between the level of internet addiction and its awareness, $\mathrm{r}(84)=-.38$. Obviously, the difference between the value systems of the two groups is small. The hypotheses of our study were partially confirmed.

\section{Discussion}

As a result of empirical research, we found that the basic values of the participants in both groups were largely similar. Based on our results, we concluded that openness to change was the most important value for a larger percentage of students using internet technologies for communication, entertainment and games (with a duration of more than 4-5 hours a day).

The values "Self-exaltation and power" ranked last among the majority of participants using internet technologies for communication, entertainment and games (longer than 4-5 hours a day) than among the participants of the second group, and "hedonism and selfenhancement" are the most important values for more than half of students using Internet technologies mainly for the purpose of learning (or less than 4-5 hours a day). "Conservatism" was expressed minimally in a large number of students using internet technologies for learning purposes (or less than 4-5 hours a day) than among students of the first group. Factors: "Strength", "Assessment", "Activity" did not correlate with the answers of the questionnaire, but correlated with preferences: students with a low level of strength and activity preferred communication via internet, on the contrary - with a high level of factors; self-control in the use of internet communications - a direct correlation of uncontrolled dependence on the internet with a high level of development of factors of strength, activity, assessment. There was no correlation of personal characteristics with the internet use for various purposes: learning, communication, entertainment or anything else and with the presence of friends in real and virtual reality. The results correlate and complement the research conducted by scientists [24, 25].

\section{Conclusions}

-A theoretical analysis of scientific literature has shown that students, as a result of personal transformations, are guided by values that allow them to make an independent choice of tasks and activities. Value guidelines in this case act as a censor of personality behavior, which determine the form of achieving the set goals.

-We analyzed the scientific literature, as a result of which we concluded that addictive behavior on the Internet is self-destructive behavior.

In our study of the influence of internet technologies on internet addiction and on the value system of a student's personality, we identified differences in groups and correlations between internet addiction, defense mechanisms, personal characteristics and value orientations of the individual. The results of the study showed that the basic values of the participants from both groups were largely similar. Our study has shown that the hypotheses were partially confirmed.

-The study of this problem gives grounds to recognize the need for further, in-depth study of Internet addiction and its impact on the system of life meanings.

\section{References}


1. S.E. Caplan, Theory and measurement of generalized problematic Internet use: A twostep approach. Computers in Human Behavior, 26(5), 1089-1097 (2010) doi:10.1016/j.chb.2010.03.012.

2. D.J. Kuss, A.M. Kristensen, O. Lopez-Fernandez, Internet addictions outside of Europe: A systematic literature review. Computers in Human Behavior, 106621 (2020) https://doi.org/10.1016/j.chb.2020.106621

3. T. Seki, K. Hamazaki, T. Natori, H. Inadera, Relationship between internet addiction and depression among Japanese university students. Journal of affective disorders 256, 668-672 (2019) https://doi.org/10.1016/j.jad.2019.06.055

4. F. Ansar, W. Ali, A. Zareef, N. Masud, S. Zahab, H. Iftikhar, Internet Addiction and Its Relationship with Depression and Academic Performance: A Cross-Sectional Study at a Medical School in Pakistan. International Journal of Medical Students, 8(3), 251-256 (2020) doi:10.5195/ijms.2020.740

5. I. Goldberg, Internet Addiction. Behaviour \& Information Technology, 24, 93-99 (2005)

6. D.J. Kuss, O. Lopez-Fernandez, Internet addiction and problematic Internet use: A systematic review of clinical research. World journal of psychiatry, 6(1), 143 (2016)

7. A.E. Voiskounsky, The Internet as a space of knowledge: psychological aspects of hypertext structures. Journal of Modern Foreign Psychology, 6(4), 7-20 (2017)

8. A.A. Acevedo, Personalistic appraisal of Maslow's needs theory of motivation: From "humanistic" psychology to integral humanism. Journal of Business Ethics, 148(4), 741-763 (2018)

9. D.J. Kuss, M.D. Griffiths, Social networking networking sites and addiction: ten lessons learned. International Journal of Environmental Research and Public Health, 14, 311 (2017) https://doi.org/10.3390/ijerph14030311

10. K. Kawabe, F. Horiuchi, M. Ochi, Y. Oka, S. Ueno, Internet addiction: prevalence and relation with mental states in adolescents. Psychiatry and Clinical Neurosciences, 70(9), 405-412 (2016) https://doi.org/10.1111/pcn.12402

11. M.H. Orzack, A.C. Voluse, D. Wolf, J. Hennen, Problem Gambling and Other Behavioural Addictions // CyberPsychology \& Behavior, 9(3), 348-360 (2006)

12. M.P. Lin, J.Y.W. Wu, J. You, W.H. Hu, C.F. Yen, Prevalence of internet addiction and its risk and protective factors in a representative sample of senior high school students in Taiwan. Journal of Adolescence, 62, 38-46 (2018) https://doi.org/10.1016/j.adolescence.2017.11.004

13. M.H. Orzack, Psychiatric Times - Computer Addiction: What Is It? // Journal of Social and Personal Relationships, 15, 519-53712 (2008)

14. M. Griffiths Technological addictions // Clinical Psychology Forum, 71, 14-19 (1995)

15. Modeling Excessive Internet Use: Revision of R. Davis's Cognitive-Behavioural Model of Pathological Internet Use Polish Psychological Bulletin October, 42(3):129139 (2011) DOI: 10.2478/v10059-011-0018-6

16. D.L. Paulhus, B. Fridhandler, S. Hayes, Psychological defense: Contemporary theory and research., Handbook of personality psychology, 543-579 (1997) http://dx.doi.org/10.1016/B978-012134645-4/50023-8

17. P.A. Kline, Critical perspective on defense mechanisms. In The concept of defense mechanisms in contemporary psychology. Springer, New York, NY, 3-13 (1993) DOI: $10.1016 / \mathrm{S} 0166-4115(04) 80027-\mathrm{X}$ 
18. J. Palombo, B.J. Koch, H.K. Bendicsen, Heinz Hartmann (1894-1970). In Guide to psychoanalytic developmental theories Springer, New York, NY, 49-60 (2009) DOI: 10.1007/978-0-387-88455-4_2

19. A. Prunas, R. Di Pierro, J. Huemer, A. Tagini, Defense mechanisms, remembered parental caregiving, and adult attachment style. Psychoanalytic Psychology, 36(1), 6472 (2019) https://doi.org/10.1037/pap0000158

20. A.J. Fuligni, The need to contribute during adolescence. Perspectives on Psychological Science, 14(3), 331-343 (2019) https://doi.org/10.1177/1745691618805437

21. M. Rokeach, J.F. Regan, The role of values in the counseling situation. The personnel and guidance Journal, 58(9), 576-582 (1980) https://doi.org/10.1002/j.21644918.1980.tb00454.x

22. A.S. Berberyan, H.S. Berberyan, Ethnopsychological aspects of the meaning-of-life and value orientations of Armenian and Russian students. Psychology in Russia, 9(1), 121 (2016)

23. K.A. Allen, M.L. Kern, D. Vella-Brodrick, L. Waters, School values: A comparison of academic motivation, mental health promotion, and school belonging with student achievement. The Educational and Developmental Psychologist, 34(1), 31-47 (2017) doi: 10.1017/edp.2017.5

24. C.H. Ko, J.Y. Yen, C.S. Chen, Y.C. Yeh, C.F. Yen, Predictive values of psychiatric symptoms for internet addiction in adolescents: a 2-year prospective study. Archives of pediatrics \& adolescent medicine, 163(10), 937-943 (2009) doi:10.1001/archpediatrics.2009.159

25. L.T. Lam, Z.W. Peng, Effect of pathological use of the internet on adolescent mental health: a prospective study. Archives of pediatrics \& adolescent medicine, 164(10), 901-906 (2010) doi:10.1001/archpediatrics.2010.159 